\title{
Analysis of Complications Development Predictors after Radical Prostatectomy
}

\author{
Vladimir Vorobev*(D), Vladimir Beloborodov ${ }^{1} \mathbb{D}$, Vladimir Luchkevich ${ }^{2} \mathbb{D}$, Dmitriy Shmakov ${ }^{3}$, Olga Baklanova ${ }^{4}$, \\ Stepan Sidorov ${ }^{1}$, Bator Sharakshinov ${ }^{1}$ (D) \\ ${ }^{1}$ Department of General Surgery and Anesthesiology, Irkutsk State Medical University, Irkutsk, Russian Federation; ${ }^{2}$ Department \\ of Public Health, Economic and Management, North-Western State Medical University named after I.I. Mechnikov, Saint \\ Petersburg, Russian Federation; ${ }^{3}$ Department of Faculty Surgery, Irkutsk State Medical University, Irkutsk, Russian Federation; \\ ${ }^{4}$ Department of Urology, GBUZ State Oncology Hospital, Irkutsk, Russian Federation
}

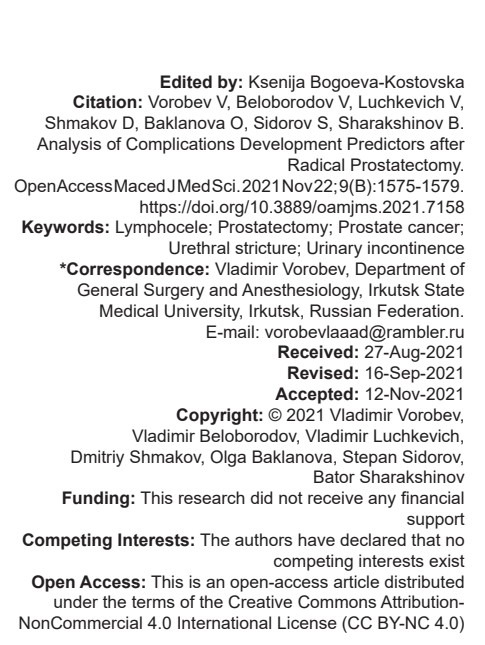

Introduction

Prostate cancer is the second most common malignant men's disease. The incidence varies widely, from 1.5 in Nepal to 115 in Australia (per 100,000 population), with the inverse mortality ratio - from 0.1 in Australia to 0.8 in Nepal (per 100,000 population) [1].

According to GLOBOCAN 2018, there were 1.3 million new cases of prostate cancer worldwide, 449.8 thousand in Europe, 297.2 thousand in Asia, and 234.3 thousand in North America. According to the $\mathrm{WHO}$, in 2018, prostate cancer among men with malignant neoplasms took $2^{\text {nd }}$ place (after lung cancer), and its share was $13.5 \%$. The number of patients with prostate cancer in the world who have been registered for 5 years has reached 3.7 million people (96.7/100 thousand population) [2], [3].

Among the male population of the Russian Federation, the incidence of malignant neoplasms in 2018 such as prostate cancer was $14.9 \%$ (2009-10.7\%),
42,518 of new cases of prostate cancer for the $1^{\text {st }}$ time. The incidence rate of prostate cancer is 62.43/100 thousand population. The increase in incidence from 2009 to 2018 reached $62.53 \%$ with an average annual growth rate of $5.92 \%$ [4].

Mortality rates are also alarming. In 2018, 13,007 people died from prostate cancer in Russia, which is $30.45 \%$ more than in 2009 (9971). Over 10 years (from 2009 to 2018), the increase in the mortality rate was $6.51 \%$ [5]. The standard treatment for prostate cancer is radical prostatectomy (RP) [6]. The cancer-specific 10-year survival rate for localized cancers after RP is $99 \%$ [7].

This surgical technique leads to typical complications such as intraoperative blood loss, urethral strictures (vesicourethral anastomosis), urinary incontinence, erectile dysfunction, lymphocele, and the ureter or rectum injury [8]. Currently, there are no convincing data on the difference in the complications' development after classical open retropubic $\mathrm{RP}(\mathrm{RRP})$ and robotic-assisted 
laparoscopic prostatectomy (RALP) RP [9], [10]. RRP has an $80-97 \%$ chance of urinary retention maintaining 1 year after surgery, compared with an 89-100\% chance after RALP. A prospective multicenter study predicts a risk ratio of urinary incontinence 1 year after treatment at 1.08 (95\% confidence interval [Cl]: $0.87-1.34)$, and odds ratio (OR) of $0.81(95 \%$ $\mathrm{Cl}$ : 0.66-0.98) for erectile dysfunction, regardless of technique (RALP vs. RRP) [11].

The lymphocele development is most likely after an extended lymph node dissection (10.3\%) compared to a limited dissection (4.6\%) [12], especially after applying an extraperitoneal approach [13]. The study aims to analyze the complications' development after RP.

\section{Materials and Methods}

The local ethical committees of (BLINDED) and (BLINDED) approved the clinical trial. The retrospective study took place at the surgical department of the (BLINDED). The clinical part of the study includes an analysis of the surgical treatment results of patients with an established diagnosis of prostate cancer for 2012-2018.

The inclusion criteria for the study were:

- The confirmed diagnosis of prostate cancer

- The patient underwent radical retropubic prostatectomy

- Multi-slice spiral computed tomography (MSCT) or magnetic resonance imaging (MRI) of the small pelvis and prostate biopsy verified the diagnosis before surgery

- $\quad$ The patient is over 18 years old

- Histological type is adenocarcinoma of the prostate.

Non-inclusion criteria:

- $\quad$ Neoadjuvant and adjuvant treatments

- $\quad$ Positive surgical margin

- Patients with distant metastasis of prostate cancer

- $\quad$ Changes in the surgical team.

Due to various reasons, the patient did not fulfill the examination and treatment standard or underwent another operation that did not meet the criteria of the group.

\section{Study group characteristics}

The study presents a retrospective analysis of clinical cases with an established diagnosis of prostate cancer from 2012 to 2018 . During this period, 52 patients met the study criteria.

\section{methods}

\section{Analysis/diagnostic and treatment}

The obligatory examination included the patients' complaints and anamnesis, an objective examination, clinical blood and urine tests, a biochemical blood test, coagulogram indices, the electrolyte blood composition analysis, X-ray and ultrasound of the abdominal cavity organs and genitourinary system, MSCT or MRI of the genitourinary system, chest, abdominal cavity, and pelvic organs, skeletal bone scintigraphy.

Surgical treatment included radical retropubic prostatectomy with preservation of the neurovascular bundle (unilateral or bilateral preservation) in localized forms; in all cases, there was extended lymph node dissection. A team of two urologists performed surgical operations. The surgical technique is standard; the vesicourethral anastomosis had six separate interrupted sutures with 3-0 monocril.

\section{Data analysis}

The authors used STATISTICA for Windows 10.0 (Statsoft, Inc, USA), Statistical Package for the Social Sciences Statistics 23.0 (IBM, USA), and Stata 14.2 (StataCorp, USA) to analyze the initial data and surgical treatment results.

\section{Preoperative parameters}

The average age of the patients was $64.2 \pm 5.49$ years. The median age of disease detection was one $(0.5 ; 2)$ month. Tables 1 and 2 present the patients' preoperative parameters.

Table 1: Staging of prostate cancer

\begin{tabular}{lll}
\hline Disease stage on TNM & $\mathrm{n}=52$ & $\%$ \\
\hline T1NxMo & 8 & 15.3 \\
T2NxMo & 31 & 59.6 \\
T3aNxMo & 4 & 7.6 \\
T3bNxMo & 9 & 17.3 \\
\hline Total points on the Gleason scale & $\mathrm{n}=52$ & $\%$ \\
\hline 6 and less & 25 & 48.0 \\
7 & 18 & 34.6 \\
8 and more & 9 & 17.3 \\
\hline
\end{tabular}

\section{Postoperative period}

After surgical treatment, all patients stayed in the intensive care unit for $12 \mathrm{~h}$. On the $12^{\text {th }}$ day after surgery, we removed the urethral catheter. 2 years after surgical treatment, we assessed long-term results.

\section{Ethics approval}

The research was conducted ethically in accordance with the World Medical Association Declaration of Helsinki. The research was approved by the local ethics committees of (BLINDED). Informed consent was signed by participants. 
Table 2: Preoperative parameters of patients in comparison groups

\begin{tabular}{ll}
\hline Parameter & $(\mathrm{n}=52)$ \\
\hline Height, $\mathrm{cm}$ & $172.7 \pm 5.8$ \\
Weight, kg & $80.0 \pm 11.9$ \\
Smoking, $\mathrm{n}(\%)$ & $3(5.7)$ \\
Myocardial infarction, $\mathrm{n}(\%)$ & $1(1.9)$ \\
Stroke, $\mathrm{n}(\%)$ & $1(1.9)$ \\
Vascular atherosclerosis, $\mathrm{n}(\%)$ & $12(23)$ \\
Heart rhythm disturbances, $\mathrm{n}(\%)$ & $4(7.6)$ \\
Hypertension, $\mathrm{n}(\%)$ & $25(48)$ \\
Diabetes, $\mathrm{n}(\%)$ & $7(13.4)$ \\
Urolithiasis, $\mathrm{n}(\%)$ & $7(13.4)$ \\
Chronic urinary tract infections, $\mathrm{n}(\%)$ & $9(17.3)$ \\
Nephroptosis, $\mathrm{n}(\%)$ & $2(3.8)$ \\
Chronic kidney disease, $\mathrm{n}(\%)$ & $3(5.7)$ \\
Kidney cysts, $\mathrm{n}(\%)$ & $11(21.1)$ \\
Kidney cancer, $\mathrm{n}(\%)$ & $1(1.9)$ \\
Varicose veins of the pelvis, $\mathrm{n}(\%)$ & $1(1.9)$ \\
Pelvic venous congestion, $\mathrm{n}(\%)$ & $3(5.7)$ \\
Erythrocytosis, $\mathrm{n}(\%)$ & $1(1.9)$ \\
Erythropenia, $\mathrm{n}(\%)$ & $2(3.8)$ \\
Anemia, $\mathrm{n}(\%)$ & $16(30.7)$ \\
Leukocytosis, $\mathrm{n}(\%)$ & $5(9.6)$ \\
Coagulopathy, $\mathrm{n}(\%)$ & $3(5.7)$ \\
Proteinuria, $\mathrm{n}(\%)$ & $18(34.6)$ \\
Leukocyturia, $\mathrm{n}(\%)$ & $8(15.3)$ \\
Hematuria, $\mathrm{n}(\%)$ & $17(32.6)$ \\
Hyperglycemia, $\mathrm{n}(\%)$ & $13(25)$ \\
Uremia, $\mathrm{n}(\%)$ & $4(7.6)$ \\
Hyponatremia, $\mathrm{n}(\%)$ & $1(1.9)$ \\
Hypernatremia, $\mathrm{n}(\%)$ & $1(1.9)$ \\
\hline
\end{tabular}

\section{Results}

\section{Treatment results}

The median period of postoperative follow-up was $48(36 ; 60)$ years. All $52(100 \%)$ patients recovered. During the observation period, there was no cancerspecific mortality among the patients included in the study. There were also no signs of the disease relapse. The average duration of the surgical operation was $177 \pm 40 \mathrm{~min}$, the volume of intraoperative blood loss was $1000(550 ; 1600) \mathrm{ml}$, with a minimum of zero and a maximum of $2000 \mathrm{ml}$.

Twelve patients had intraoperative periprostatic fibrosis $(23 \%)$. The intraoperative ureteral injury occurred in one $(1.9 \%)$ case. Urinary incontinence 24 months after surgery persisted in $10(19.2 \%)$ cases, mild (<one pad/day) for eight $(15.3 \%)$, moderate (no more than 2 pads/day) for two (3.8\%) patients. The dynamics of the continent's recovery after 24 months revealed the absence of the indicator increase.

Five $(9.6 \%)$ patients had vesicourethral anastomosis strictures. All cases required endoscopic correction (DVIU), in case of recurrence - urethroplasty surgery $(n=2,3.8 \%)$. As a result, all patients are relieved of bladder outlet obstruction. Six $(11.5 \%)$ patients had postoperative lymphocele and two $(3.8 \%)$ patients required therapeutic actions (puncture or surgical revision and drainage). A rare complication was Studer ileoconduitis injury in a patient with prostate cancer after the apical resection of the prostate during radical cystectomy.

\section{Logistic analysis}

To determine the predictors of complications, we performed univariate and multivariate logistic regression analysis. Predictor variables came out of the initial parameters (partially displayed in Tables 1 and 2), as well as intraoperative data. Table 3 presents information on predictor factors (univariate and multivariate logistic regression analysis).

The results helped to build a model for predicting the risk of high blood loss (more than $1000 \mathrm{ml}$ ). Univariate analysis revealed no reliable $(p<0.05)$ predictors. A multivariate analysis of predictors with a significance level of $p<0.2$ revealed no reliable predisposing variables. Thus, there were no predictors of excessive blood loss.

Univariate analysis of the maintaining incontinence risk 2 years after surgical treatment

Table 3: Predictors of complications after RP

\begin{tabular}{|c|c|c|c|c|c|c|}
\hline \multirow[t]{2}{*}{ Complication } & \multirow[t]{2}{*}{ Sign } & \multicolumn{3}{|c|}{ Univariate analysis } & \multicolumn{2}{|l|}{ Multivariate analysis } \\
\hline & & $x^{2}$ & OR $(95 \% \mathrm{Cl})$ & $\mathrm{p}$ & $\mathrm{OR}(95 \% \mathrm{Cl})$ & $\mathrm{p}$ \\
\hline More than $1000 \mathrm{ml}$ of blood loss & Over 70 years old & 0.96 & $-0.05(-0.1 ; 0.05)$ & 0.334 & - & - \\
\hline \multirow{6}{*}{ Multivariate Logit Regression: $\chi^{2}=7.25 ; p<0.026$} & Vascular atherosclerosis & 3.43 & $-1.4(-3.0 ; 0.2)$ & 0.092 & $-1.3(-3.0 ; 0.32)$ & 0.113 \\
\hline & Urolithiasis disease & 1.16 & $0.8(-0.7 ; 2.4)$ & 0.285 & - $\quad-1$ & - \\
\hline & Initial anemia & 1.28 & $0.6(-0.5 ; 1.8)$ & 0.258 & - & - \\
\hline & Hyperglycemia & 4.3 & $-1.5(-3.1 ; 0.8)$ & 0.063 & $-1.5(-3.1 ; 0.15)$ & 0.076 \\
\hline & More than $3 \mathrm{~h}$ of operation & 2.14 & $0.8(-0.2 ; 1.9)$ & 0.147 & - & - \\
\hline & Periprostatic fibrosis & 2.55 & $1.0(-0.2 ; 2.3)$ & 0.114 & - & - \\
\hline Urinary incontinence after 24 months Multivariate Logit Regression: & Height over $175 \mathrm{~cm}$ & 1.18 & $-0.06(-0.19 ; 0.05)$ & 0.291 & - & - \\
\hline \multirow{7}{*}{$\chi^{2}=14.24 ; p<0.006$} & Obesity & 1.88 & $-0.04(-0.11 ; 0.02)$ & 0.199 & $-0.08(-0.18 ; 0.1)$ & 0.080 \\
\hline & Vascular atherosclerosis & 1.38 & $-1.1(-3.3 ; 1.01)$ & 0.296 & - & - \\
\hline & Hypertonic disease & 4.16 & $-1.5(-3.2 ; 0.08)$ & 0.063 & $-1.1(-3.0 ; 0.64)$ & 0.203 \\
\hline & Hyperglycemia & 1.73 & $-1.2(-3.4 ; 0.89)$ & 0.248 & - & - \\
\hline & Non-Nerve-sparing RRP & 5.14 & $-0.7(-1.4 ; 0.02)$ & 0.050 & $-0.9(-1.9 ;-0.07)$ & 0.035 \\
\hline & More than $3 \mathrm{~h}$ of operation & 1.35 & $0.009(-0.006 ; 0.02)$ & 0.241 & - & - \\
\hline & Blood loss of more than $1000 \mathrm{ml}$ & 2.37 & $1.09(-0.31 ; 2.5)$ & 0.129 & $0.001(-0.0002 ; 0.002)$ & 0.74 \\
\hline Vesicourethral anastomosis strictures & Obesity & 1.87 & $-0.06(-0.16 ; 0.03)$ & 0.213 & $-0.05(-0.2 ; 0.12)$ & 0.534 \\
\hline \multirow[t]{3}{*}{ Multivariate Logit Regression: $\chi^{2}=19.09 ; p<0.0008$} & Previous transurethral surgery & 13.77 & $4.0(1.5 ; 6.5)$ & 0.001 & $6.09(0.71 ; 11.4)$ & 0.026 \\
\hline & Chronic cystitis & 2.5 & $1.7(-0.2 ; 3.7)$ & 0.094 & $-0.01(-4.0 ; 4.0)$ & 0.995 \\
\hline & Operating blood loss $>300 \mathrm{ml}$ & 1.98 & -0.001 (small diap) & 0.191 & $-0.002(-0.006 ; 0.001)$ & 0.162 \\
\hline Lymphocele & Height over $180 \mathrm{~cm}$ & 3.99 & $0.15(-0.007 ; 0.31)$ & 0.061 & & \\
\hline \multirow[t]{6}{*}{ Multivariate Logit Regression: $\chi^{2}=17.56 ; p<0.0006$} & Obesity & 10.21 & $0.12(0.03 ; 0.21)$ & 0.008 & & \\
\hline & Diabetes & 5.59 & $2.3(0.45 ; 4.2)$ & 0.015 & & \\
\hline & Chronic cystitis & 1.82 & $1.4(-0.5 ; 3.3)$ & 0.153 & & \\
\hline & Coagulopathy & 5.67 & $3.1(0.5 ; 5.7)$ & 0.019 & & \\
\hline & More than $3 \mathrm{~h}$ of operation & 4.84 & $2.1(-0.08 ; 4.3)$ & 0.059 & & \\
\hline & Blood loss of more than $1000 \mathrm{ml}$ & 2.21 & $1.3(-0.4 ; 3.1)$ & 0.151 & & \\
\hline
\end{tabular}


established Non-Nerve-sparing RRP as a significant predictor $(p<0.05)(\mathrm{OR}-0.7 ; 95 \% \mathrm{Cl}-1.4 ; 0.02$; $p=0.05)$, other factors were not significant $(p>0.05)$. A multivariate analysis (predictors with a $p<0.2$ level) also established Non-Nerve-sparing RRP as a significant predictor of maintaining incontinence (OR-0.9; 95\% $\mathrm{Cl}-1.9 ;-0.07 ; \mathrm{p}=0.035)$, which indicates a $90 \%$ risk of persisting urinary incontinence after Non-Nervesparing RRP.

Previous transurethral surgeries (OR 4.0; 95\% Cl $1.5 ; 6.5 ; p=0.001$ ) became an independent predictor of the vesicourethral anastomosis stricture $(p<0.05)$. A multivariate analysis (predictors with a $p<0.2$ level) demonstrated a similar pattern (OR 6.09; 95\% Cl 0.71; $11.4 ; p=0.026)$, which indicates a 6 times risk of developing such complication if the patient already had one or more transurethral surgery.

Obesity (OR 0.12; 95\% Cl 0.03; 0.21; $p=0.008$ ), diabetes (OR 2.3; 95\% Cl 0.45), and coagulopathy (OR 3.1; 95\% Cl 0.5; 5.7; $p=0.019$ ) were independent predictors of lymphocele $(p<0.05)$. 4.2; $p=0.015)$. A multivariate analysis (predictors with $p<0.2$, then $p<0.1$ and $p<0.05$ ) did not give reliable results.

\section{Discussion}

The obtained results correlate with the data presented earlier in scientific publications. The comparative analysis is difficult due to the small number of works on the predictors of a specific type of complications after RRP. The incidence of identified complications among the cases included in the study is slightly lower than the average data in large metaanalyses [8]. It is necessary to continue the study in larger samples and compare the obtained data with the results of other authors. A significant advantage of this study is an isolated analysis (no relapse, one team of surgeons, no positive surgical margin, no other methods of treatment, and some others), of various factors, influence the likelihood of postoperative complications, one important disadvantage is a small sample size.

The study did not demonstrate the correlation between significant blood loss and any of the factors, or the effect of blood loss on any complications development, which is likely due to the relatively small sample size. Thus, in a large study [14], the Surgical Apgar Score (SAS) demonstrated the connection between intraoperative blood loss and the development of complications. Each 1-point increase in SAS after open RP resulted in a $24 \%$ reduction in the chances of any complication (95\% Cl 0.66-0.88).

Vesicourethral anastomosis strictures occur in 5-8\% of cases after RP. Such a complication requires subsequent surgical correction using transurethral scar resection or perineal reanastomosis [15]. The correction of all cases of post-RP urethral strictures was successful. The obtained data established 6 times risk of strictures development after previous transurethral surgeries are fully consistent with the current concept of the urethral stricture disease problem [16], [17]. Some studies have demonstrated the connection between the risk of developing anastomotic stricture and the time of catheter removal [18]. However, for this study, it is not possible to trace the factor due to the programmed removal of the catheter on the $12^{\text {th }}$ day.

In a previously published study of incontinence predictors 24 months after surgery, significant factors were age (OR 1.130; $p=0.030)$, surgery duration (OR 1.009; $p=0.005$ ), and previous transurethral resection of the prostate (OR $0.218 ; p=0.034)$, which do not correspond to the data obtained by the authors. Surgery duration factor (up to 2.2-3 and more than $3 \mathrm{~h}$ ), previous transurethral surgery, and age did not show the connection with the risk of maintaining incontinence. The obtained data on an increase in the likelihood of urinary incontinence after Non-Nerve-sparing RRP indirectly indicate a positive role of the neurovascular bundle preservation and less trauma in localized malignant processes. The obtained data correlate with another study indicating the best continental outcomes (OR, 4.77; 95\% Cl 2.18; 10.44; $p=0.0001)$ after Nervesparing RRP [19].

Lymphocele is a typical complication with a probability of up to $15-40 \%$ in general, and significant lymphocele requiring treatment up to $2.6-5 \%$ [20], [21]. According to previously published scientific works [20], there were no predictors of this complication. There was evidence [22] about the role of age and the absence of the obesity factor influence (OR 1.14; $p=0.08$ ). Our results on a 2 times risk of lymphocele in diabetes and a 3 times risk in coagulopathies require further study.

The study revealed some new information on the possible predictors of complications such as urinary incontinence in the late period, the lymphocele, and stricture of the vesicourethral anastomosis. Some of the results require further study and confirmation.

\section{Conclusions}

Radical prostatectomy results in typical complications such as intraoperative blood loss, urethral strictures (vesicourethral anastomosis), urinary incontinence, erectile dysfunction, lymphocele, and the ureter or rectum injury. The development of complications after radical prostatectomy was analyzed. A multivariate analysis established Non-Nerve-sparing RRP (OR-0.9; 95\% Cl-1.9; -0.07; p=0.035) as a significant incontinence predictor after 2 years. It was also established previous transurethral operations as a 
significant predictor of the vesicourethral anastomosis stricture. Some of the results require further study and confirmation.

\section{References}

1. Kimura T, Egawa S. Epidemiology of prostate cancer in Asian countries. Int J Urol. 2018;25(6):524-31. https://doi.org/10.1111/ iju. 13593

\section{PMid:29740894}

2. Bray F, Ferlay J, Soerjomataram I, Siegel RL, Torre LA Jemal A. Global cancer statistics 2018: GLOBOCAN estimates of incidence and mortality worldwide for 36 cancers in 185 countries. CA Cancer J Clin. 2018;68(6):394-424. https://doi. org/10.3322/caac.21492

PMid:30207593

3. Siegel RL, Miller KD, Jemal A. Cancer statistics, 2018. CA Cancer J Clin. 2018;68(1):7-30. https://doi.org/10.3322/ caac. 21442 PMid:29313949

4. Kaprin AD, Starinsky VV, Petrova GV. Malignant Neoplasms in Russia in 2018 (Morbidity and Mortality). FGBU MNIOI Them. Moscow: P. A. Herzen; 2019.

5. Merabishvili VM. Medium-term prognosis of cancer mortality among the population of Russia. Sib J Oncol. 2019;4(18):5-12. https://doi.org/10.21294/1814-4861-2019-18-4-5-12

6. Kim EH, Bullock AD. Surgical management for prostate cancer. Mo Med. 2018;115(2):142-5.

PMid:30228706

7. Hamdy FC, Donovan JL, Lane JA, Mason M, Metcalfe C, Holding P. 10-year outcomes after monitoring, surgery, or radiotherapy for localized prostate cancer. $\mathrm{N}$ Engl J Med 2016;375(15):1415-24. https://doi.org/10.1056/nejmoa1606220 PMid:27626136

8. Pompe RS, Beyer B, Haese A, Preisser F, Michl U, Steuber T. Postoperative complications of contemporary open and robotassisted laparoscopic radical prostatectomy using standardized reporting systems. BJU Int. 2018;122(5):801-7. https://doi. org/10.1111/bju.14369

PMid:29727912

9. Novara G, Ficarra V, Mocellin S, Ahlering TE, Carroll PR, Graefen M. Systematic review and meta-analysis of studies reporting oncologic outcome after robot-assisted radical prostatectomy. Eur Urol. 2012;62(3):382-404. https://doi. org/10.1016/j.eururo.2012.05.047

\section{PMid:22749851}

10. Maffezzini M, Seveso M, Taverna G, Giusti G, Benetti A Graziotti P. Evaluation of complications and results in a contemporary series of 300 consecutive radical retropubic prostatectomies with the anatomic approach at a single institution. Urol. 2003;61(5):982-6. https://doi.org/10.1016/ S0090-4295(02)02517-7

PMid: 12736020

11. Haglind E, Carlsson S, Stranne J, Wallerstedt A, Wilderäng U, Thorsteinsdottir T. Urinary incontinence and erectile dysfunction after robotic versus open radical prostatectomy: A prospective, controlled, nonrandomised trial. Eur Urol. 2015;68(2):216-25. https://doi.org/10.1016/j.eururo.2015.02.029

PMid:25770484

12. Fossati N, Willemse PP, van den Broeck T, van den Bergh RC, Yuan $\mathrm{CY}$, Briers $\mathrm{E}$. The benefits and harms of different extents of lymph node dissection during radical prostatectomy for prostate cancer: A systematic review. Eur Urol. 2017;72(1):84-109. https://doi.org/10.1016/j.eururo.2016.12.003

PMid:28126351

13. Ploussard G, Briganti A, de la Taille A, Haese A, Heidenreich A, Menon M. Pelvic lymph node dissection during robot-assisted radical prostatectomy: Efficacy, limitations, and complications-a systematic review of the literature. Eur Urol. 2014;65(1):7-16. https://doi.org/10.1016/j.eururo.2013.03.057

PMid:23582879

14. Orberger $M$, Palisaar J, Roghmann F, Mittelstädt $L$, Bischoff $P$, Noldus J. Association between the surgical Apgar score and perioperative complications after radical prostatectomy. Urol Int. 2017;98(1):61-70. https://doi.org/10.1159/000450795 PMid:27907923

15. Beck V, Apfelbeck M, Chaloupka M, Kretschmer A, Strittmatter F, Tritschler S. Stricture of the vesicourethral anastomosis after radical prostatectomy. Urol A. 2018;57(1):29-33. https://doi. org/10.1007/s00120-017-0550-x

\section{PMid:29209754}

16. Lumen N, Hoebeke P, Willemsen P, de Troyer B, Pieters R, Oosterlinck W. Etiology of urethral stricture disease in the 21st century. J Urol. 2009;182(3):983-7. https://doi. org/10.1016/j.juro.2009.05.023

PMid:19616805

17. Shahrour W, Hodhod A, Kotb A, Prowse O, Elmansy H. Dorsal buccal mucosal graft urethroplasty for vesico-urethral anastomotic stricture postradical prostatectomy. J Urol. 2019;130:210. https://doi.org/10.1016/j.urology.2019.04.022 PMid:31039367

18. Altinova S, Serefoglu EC, Ozdemir AT, Atmaca AF, Akbulut Z, Balbay MD. Factors affecting urethral stricture development after radical retropubic prostatectomy. Int Urol Nephrol. 2009;41(4):881-4. https://doi.org/10.1007/s11255-008-9519-4 PMid: 19165616

19. Kessler TM, Burkhard FC, Studer UE. Nerve-sparing open radical retropubic prostatectomy. Eur Urol. 2007;51(1):90-7. https://doi.org/10.1016/j.eururo.2006.10.013

PMid:17074431

20. Heers $H$, Laumeier $T$, Olbert PJ, Hofmann R, Hegele A. Lymphoceles post-radical retropubic prostatectomy: A retrospective evaluation of epidemiology, risk factors, and outcome. Urol Int. 2015;95(4):400-5. https://doi. org/10.1159/000381463

PMid:25871980

21. Stolzenburg JU, Kyriazis I, Liatsikos E. Postoperative lymphocele formation after pelvic lymph node dissection at the time of radical prostatectomy should not be considered an inevitable consequence of the approach. Eur Urol. 2017;71(2):159-60. https://doi.org/10.1016/j.eururo.2016.08.046 PMid:27595375

22. Tsaur I, Thomas C. Risk factors, complications, and management of lymphocele formation after radical prostatectomy: A minireview. Int J Urol. 2019;26(7):711-6. https://doi.org/10.1111/ iju.13964

PMid:30939628 